\title{
Efficacy of coronary angioplasty for the treatment of hibernating myocardium
}

\author{
F Fath-Ordoubadi, K J Beatt, N Spyrou, P G Camici
}

\begin{abstract}
Objectives-To determine the efficacy of coronary angioplasty as the sole method of revascularisation in patients with coronary artery disease and chronically dysfunctional but viable myocardium (hibernating myocardium), and to assess the effect of restenosis on functional outcome.

Design and patients-24 consecutive patients with hibernating myocardium were studied. Positron emission tomography was used to assess myocardial viability, blood flow, and flow reserve. One patient refused angioplasty, one had bypass surgery, and one died while waiting for an elective procedure. The procedure failed in three patients. The remaining 18 patients had repeat echocardiography, 15 had repeat coronary angiography, and nine had repeat assessments of blood flow and flow reserve at mean (SD) 17 (2) weeks after angioplasty. In three patients restenosis was documented.
\end{abstract}

Results-The wall motion score index in the revascularised territories improved from $1.71(0.37)$ to $1.34(0.47)(p=0.008)$. Thirty of 51 dysfunctional segments improved in territories without restenosis compared with three of 14 in restenosed territories $(p=0.001)$. Hibernating and normal segments had comparable flows $\left(\begin{array}{llllll}0.82 & (0.26) & v & 0.89 & (0.24) & \mathrm{ml} / \mathrm{min} / \mathrm{g} ; \mathrm{NS})\end{array}\right.$ while flow reserve was lower in hibernating segments (1.55 (0.68) $v 2.07$ (1.08); $\mathbf{p}=\mathbf{0 . 0 3})$. In segments without restenosis flow reserve improved from 2.03 (1.25) to 2.33 (1.4) $(p=0.03)$. Sensitivity, specificity, and positive and negative predictive accuracy of the viability study were $97 \%$, $77 \%, 82 \%$, and $96 \%$, respectively. After excluding patients with restenosis, specificity and positive predictive accuracy improved to $90 \%$ and $93 \%$.

Conclusions-Angioplasty improves function in hibernating myocardium, and restenosis prevents recovery; hibernating myocardium is characterised by an impairment of flow reserve; restenosis affects the diagnostic accuracy of viability studies.

(Heart 1999;82:210-216)

Keywords: coronary artery disease; percutaneous transluminal coronary angioplasty; myocardial hibernation; myocardial blood flow; positron emission tomography

Correspondence to: Professor Camici. email:paolo@cu.rpms.ac.uk

Accepted for publication 24 February 1999

The main indication for percutaneous transluminal coronary angioplasty (PTCA) is to relieve angina in patients with single vessel coronary artery disease. ${ }^{1}$ However, with improvements in the technique and expertise, the indications for this procedure are widening. ${ }^{2}$ At present, patients with complex multivessel coronary artery disease are revascularised by PTCA. ${ }^{3}$ Recent trials comparing coronary bypass surgery (CABG) with PTCA in patients with multivessel coronary artery disease ${ }^{2}$ have reported comparable survival rates for the two techniques.

It has been shown in several studies that coronary revascularisation can lead to functional improvement of chronically dysfunctional but viable (hibernating) myocardium in patients with coronary artery disease. ${ }^{4}$ In most instances either CABG alone ${ }^{5-10}$ or a mixture of CABG and PTCA ${ }^{11-17}$ were used, and in those studies in which PTCA alone was employed, follow up angiography was not systematically performed to assess the adequacy of reperfusion and vessel patency. ${ }^{18}{ }^{19}$ This is particularly important as the restenosis rate in these patients may be more than $40 \% .{ }^{20-22}$ Our aim in the present study was therefore to assess the efficacy of PTCA alone for the revascularisation of hibernating myocardium, the presence of which was predicted by positron emission tomography (PET). In addition, by performing follow up angiography, we investigated the impact of restenosis on the functional outcome after PTCA and the diagnostic accuracy of PET.

\section{Methods}

STUDY POPULATION

We recruited 24 consecutive patients (23 men, one woman; mean (SD) age 62 (10) years) who were selected to undergo PTCA; they all had coronary artery disease and at least one chronically dysfunctional left ventricular region supplied by a diseased coronary artery with stenosis of $\geqslant 70 \%$. One patient had an acute myocardial infarction two months before enrolment, while none of the others had myocardial infarction or unstable angina in the six months preceding the study. In all but one patient the most recent myocardial infarct or unstable symptom was more than six months before enrolment into the study. Three patients had diabetes mellitus, four were hypertensive, and two had both diabetes and hypertension.

Of the 24 patients, one died from a ruptured abdominal aortic aneurysm before the procedure, one refused treatment with PTCA, and one patient with three vessel coronary artery disease was felt to be more suitable for CABG 
Table 1 Baseline characteristics and functional status of patients before and after percutaneous transluminal coronary angiography (PTCA)

\begin{tabular}{|c|c|c|c|c|c|c|c|}
\hline Patient & Sex & Age (years) & $\begin{array}{l}\text { WMSI } \\
\text { pre-PTCA }\end{array}$ & $\begin{array}{l}\text { WMSI } \\
\text { post-PTCA }\end{array}$ & $\begin{array}{l}E F \% \\
(\text { pre-PTCA) }\end{array}$ & $\begin{array}{l}E F \% \\
\text { (post-PTCA) }\end{array}$ & PTCA vessels \\
\hline 1 & M & 44 & 1.83 & 1.83 & 25 & 28 & OM1 \\
\hline 2 & M & 45 & 2.00 & 2.00 & 31 & 35 & LAD \\
\hline 3 & M & 62 & 1.31 & 1.06 & 36 & 51 & RCA \\
\hline 4 & M & 61 & 1.69 & 1.31 & 37 & 52 & LAD \\
\hline 5 & $\mathrm{M}$ & 76 & 1.38 & 1.38 & 32 & 28 & RCA \\
\hline 6 & M & 55 & 1.25 & 1.00 & 37 & 39 & RCA \\
\hline 7 & M & 61 & 1.81 & 1.94 & 31 & 34 & LAD \\
\hline 8 & M & 60 & 1.38 & 1.38 & 47 & 43 & LAD \\
\hline 9 & M & 71 & 1.38 & 1.19 & 48 & 48 & LAD \\
\hline 10 & M & 62 & 1.75 & 1.25 & 37 & 38 & LAD \\
\hline 11 & M & 79 & 1.13 & 1.00 & 57 & 61 & LAD \\
\hline 12 & M & 58 & 1.50 & 1.25 & 56 & 58 & LAD, CX \\
\hline 13 & M & 59 & 1.27 & 1.00 & 39 & 44 & RCA \\
\hline 14 & M & 73 & 1.94 & 1.81 & 35 & 30 & CX \\
\hline 15 & M & 73 & 1.63 & 1.88 & 36 & 31 & LAD \\
\hline 16 & $\mathrm{~F}$ & 73 & 1.19 & 1.00 & 57 & 57 & LAD, RCA \\
\hline 17 & M & 53 & 1.67 & 2.00 & 29 & 38 & LAD \\
\hline 18 & $\mathrm{M}$ & 58 & 1.25 & 1.25 & 61 & 61 & RCA \\
\hline Mean (SD) & & $62(10)$ & $1.52(0.27)$ & $1.42(0.38)$ & $41(11)$ & $43(11)$ & \\
\hline
\end{tabular}

$\mathrm{CX}$, circumflex coronary artery; EF, ejection fraction; LAD, left anterior descending coronary artery; OM1, first obtuse marginal branch; RCA, right coronary artery; WMSI, wall motion score index.

three patients with chronically occluded arteries. The 18 remaining patients had successful PTCA. Their main clinical characteristics are given in table 1 . Of these 18 patients, 10 had symptoms of stable angina and cardiac failure (New York Heart Association (NYHA) functional class II), four had anginal symptoms only, three had cardiac failure symptoms only (NYHA class II), and one denied any symptoms but had a positive exercise test for myocardial ischaemia.

STUDY PROTOCOL

To confirm the chronicity of the wall motion abnormality, regional left ventricular function was assessed qualitatively on two separate occasions six to eight weeks apart using contrast left ventriculography - first at the time of diagnostic coronary angiography, and second immediately before PTCA. In addition, echocardiography was used to assess the regional wall motion score and ejection fraction before and at mean (SD) 17 (2) weeks after the PTCA.

Tissue viability was assessed in all patients before revascularisation by measuring the myocardial uptake of ${ }^{18} \mathrm{~F}$-fluorodeoxyglucose
(FDG) by PET during euglycaemic hyperinsulinaemic clamp. Absolute myocardial blood flow was measured by PET at rest and during hyperaemia (dipyridamole, $0.56 \mathrm{mg} / \mathrm{kg}$ ) in 17 patients before PTCA and a repeat measurement was carried out in nine after revascularisation (fig 1). PTCA was considered successful if the residual stenosis was $<30 \%$ of luminal diameter after balloon dilatation, and restenosis was considered to have occurred if a stenosis of $>50 \%$ was present at the site of PTCA on follow up angiography. All the PTCA procedures were performed by the same investigators.

The study protocol was approved by the ethics committee of Hammersmith Hospital, and radiation exposure was licensed by the UK Administration of Radioactive Substances Advisory Committee. All patients gave informed and written consent before the study.

\section{ECHOCARDIOGRAPHY}

Echocardiography was performed in conventional views. Images were digitised and cineloops were stored on disk for later review. For the analysis of wall motion, the left ventricle was divided into 16 segments, according to

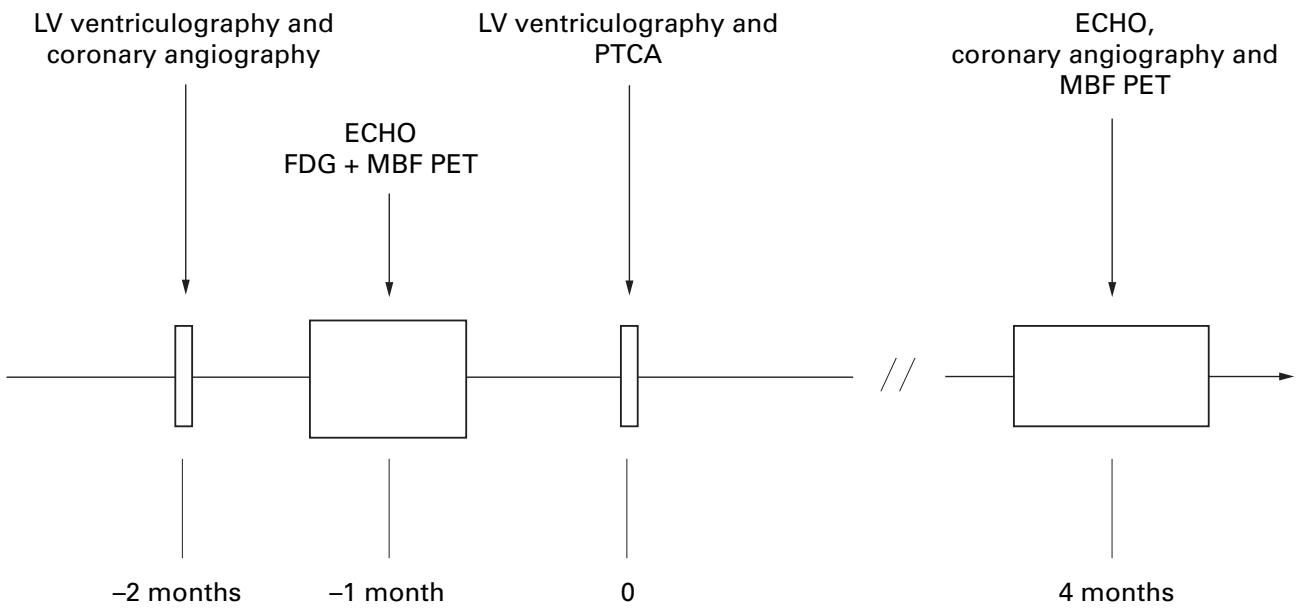

Figure 1 Schematic representation of study protocol. LV, left ventricle; $E C H O$, echocardiography; FDG, ${ }^{18} \mathrm{~F}$-fluorodeoxyglucose; MBF, myocardial blood flow; PET, positron emission tomography; PTCA, percutaneous transluminal coronary angioplasty. 
the American Society of Echocardiography guidelines. ${ }^{23}$ All studies were read by two investigators at random, blinded to patient's name and clinical details. Functional improvement of individual segments after PTCA was defined as an improvement in resting wall motion score of one grade. The 16 ventricular segments were grouped into three vascular territories: the left anterior descending (LAD), the circumflex (CX), and the right coronary artery (RCA) territory, according to anatomical distribution of each artery. ${ }^{23}$ Wall motion was assessed visually, using both endocardial motion and wall thickening, ${ }^{23}$ according to the following scoring system: normal, 1; hypokinetic, 2; akinetic, 3. The wall motion score index (WMSI) was derived for the entire left ventricle and for each vascular territory using the sum of individual scores divided by the respective number of segments.

POSITRON EMISSION TOMOGRAPHY

The PET study was carried out during hyperinsulinaemic euglycaemic clamp, according to the protocol proposed by De Fronzo et al..$^{24}$ Technical details of the scanner ${ }^{26}$ and protocol used to measure myocardial blood flow $^{27}$ and FDG uptake $e^{25}$ have been described in detail previously. Briefly, following optimisation of patient's position using a rectilinear scan, a 20 minute transmission scan was performed to correct the emission scans for tissue attenuation. Myocardial blood flow was measured at rest and after an intravenous injection of dipyridamole $(0.56 \mathrm{mg} / \mathrm{kg}$ over four minutes) using ${ }^{15} \mathrm{O}$ labelled water. The coronary flow reserve was computed as the ratio of dipyridamole myocardial blood flow to resting myocardial blood flow. Myocardial glucose utilisation was then measured by infusing FDG intravenously (185 MBq) over a two minute period after a steady state of euglycaemia was achieved, as previously reported. ${ }^{25}$

PET DATA ANALYSIS

Myocardial blood flow ( $\mathrm{ml} / \mathrm{min} / \mathrm{g}$ of water perfusible tissue) and the metabolic rate of glucose (MRG, $\mu \mathrm{mol} / \mathrm{min} / \mathrm{g}$ ) were calculated as previously reported. ${ }^{25}$ The planes of the last FDG frame in short axis view were grouped into

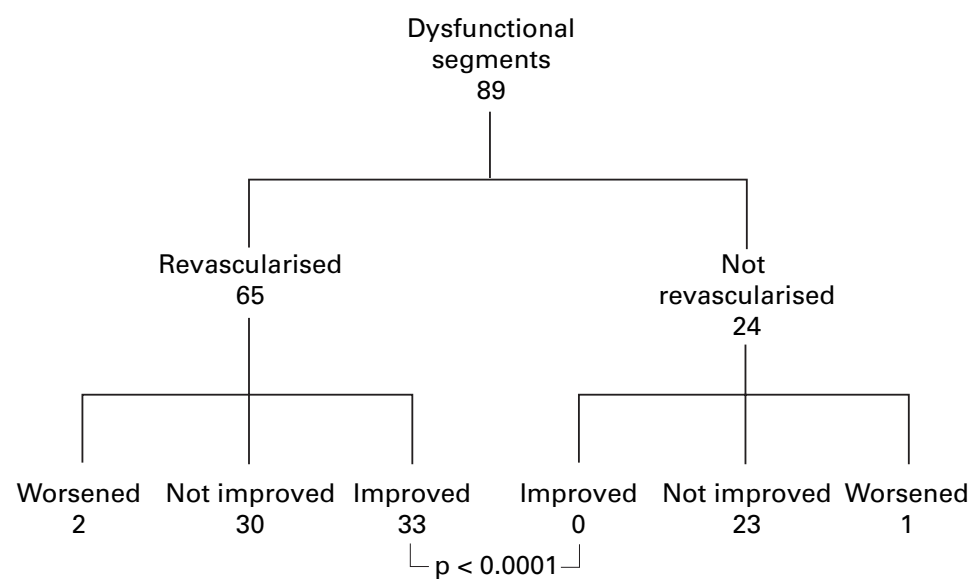

Figure 2 Chart showing comparison of changes in function in revascularised versus non-revascularised dysfunctional segments in the 15 patients who underwent percutaneous transluminal coronary angioplasty and follow up angiography. basal, mid, and apical regions. In the basal and mid planes, six sectors corresponding to the anterior, septal, anteroseptal, lateral, inferior, and posterior myocardium and in the apical planes four sectors corresponding to anterior, septal, lateral, and inferior were drawn. In this way we obtained myocardial blood flow and MRG values for 16 regions corresponding to the echocardiographic regions.

\section{STATISTICS}

Continuous data are expressed as mean (SD). Comparison between paired data sets was made with Student's paired $t$ test and between unpaired data sets with Student's unpaired $t$ test. Comparison of more than two mean values was performed using one way analysis of variance for repeated measures, and Fisher's least significant difference method was subsequently applied to localise the source of the difference. Univariate analysis for categorical variables was performed using the $\chi^{2}$ test. The Pearson correlation coefficient was calculated for normally distributed variables. A value of $\mathrm{p}<0.05$ was considered significant.

\section{Results}

PTCA

Twenty vessels were dilated in the 18 patients who had successful revascularisation (table 1). The target vessel was the left anterior descending coronary artery in nine cases, the left anterior descending and right coronary artery in one case, the left anterior descending and circumflex artery in one case, the right coronary artery in five cases, and the circumflex artery in two cases. None of the patients had any serious complication during or after the procedure. All patients had repeat echocardiography and 15 had follow up coronary angiography at 17 (2) weeks. In 12 there was no evidence of restenosis, while restenosis had occurred in three. In all these three cases the restenosis was more than $70 \%$ but less than $99 \%$. Nine patients had a repeat PET study for measurement of myocardial blood flow and coronary flow reserve within a week of repeat coronary angiography (fig 1). Visual inspection of two ventriculograms taken before the PTCA, with a mean interval of two months, showed no change in regional left ventricular function, confirming the chronicity of the condition.

FUNCTIONAL CHANGES AFTER PTCA AND EFFECT OF RESTENOSIS ON FUNCTIONAL OUTCOME There were 235 adequately visualised segments in the 15 patients who had successful PTCA with angiographic follow up. These comprised 146 normal segments (62\%) and 89 dysfunctional segments (38\%), of which $66(74 \%)$ were hypokinetic and $23(26 \%)$ akinetic. Sixty five dysfunctional segments $(73 \%)$ were revascularised. Two segments worsened and were discarded. Of the remaining 63 segments, 33 $(52 \%)$ improved after PTCA. In contrast, of 24 dysfunctional segments that were not revascularised, none improved at follow up $(p<0.0001)$; one segment worsened and was therefore discarded (fig 2). 


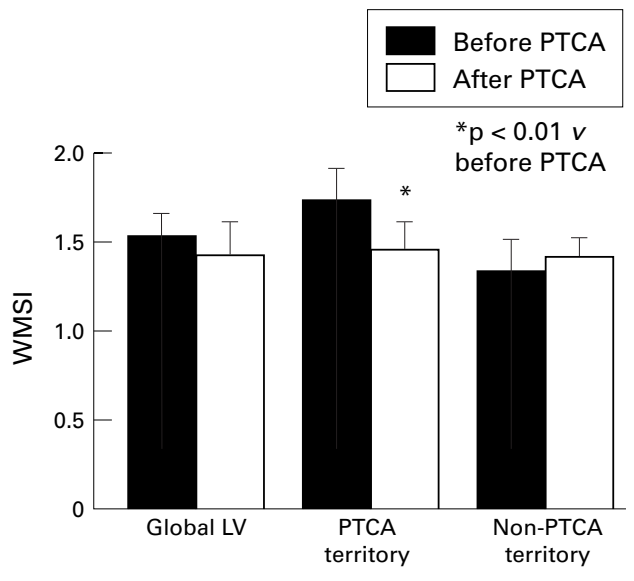

Figure 3 Changes in global and regional wall motion score index (WMSI) after percutaneous transluminal coronary angioplasty (PTCA).

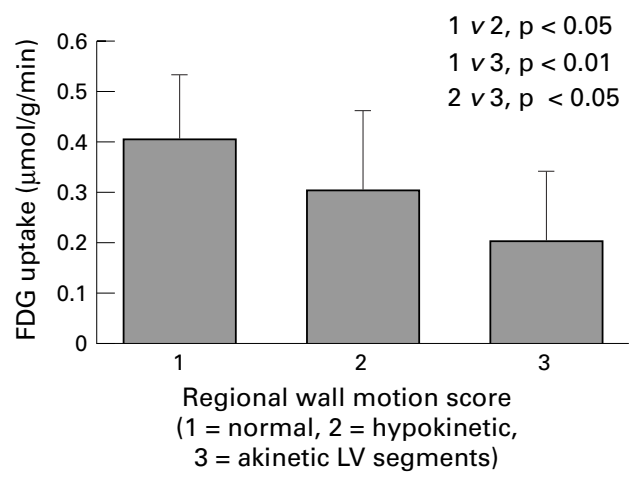

Figure 4 Diminishing ${ }^{18}$ F-fluorodeoxyglucose (FDG) uptake with increasing severity of wall motion abnormality.

Thirty of 51 dysfunctional segments (59\%) improved in patients with no restenosis compared with three of $14(21 \%)$ in patients with restenosis $(p=0.01)$. These three segments belonged to one patient who had developed extensive collaterals supplying the territory of the restenosed artery. Ejection fraction (42 (11) $v 45$ (11), $\mathrm{p}=0.08)$ and WMSI (1.49 (0.28) v 1.39 (0.41), $\mathrm{p}=0.1)$ did not improve significantly after revascularisation. After excluding the data from the patients with restenosis, the improvement in ejection fraction became statistically significant $(41$ (10) v

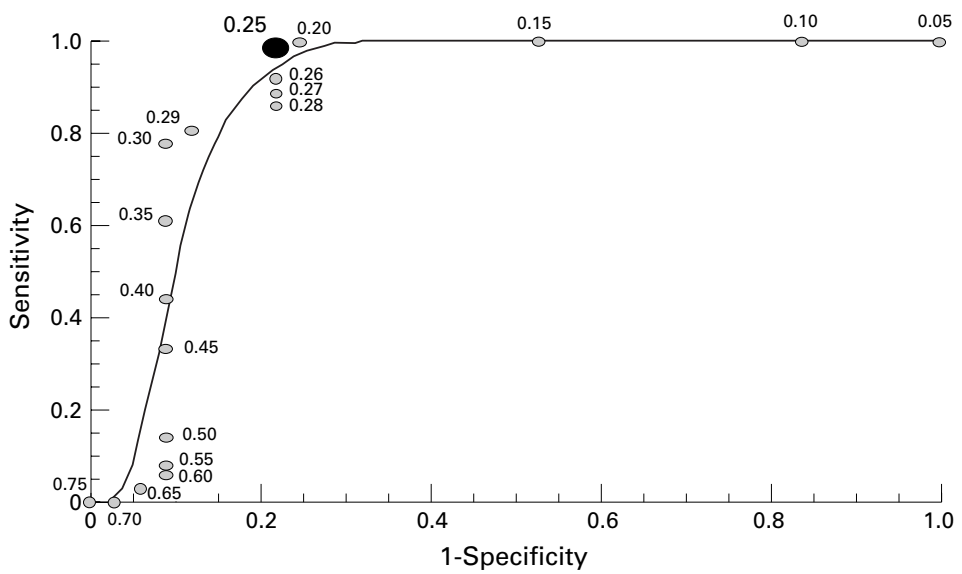

Figure 5 A receiver-operator characteristic (ROC) curve showing sensitivity and specificity in identifying hibernating segments for different values of metabolic rate of glucose (MRG) in $\mu \mathrm{mol} / \mathrm{g} / \mathrm{min}$. The large dot represents the operating point associated with the best compromise between sensitivity and specificity.
$45(10), \mathrm{p}=0.04)$, though the WMSI did not $(1.51(0.31) v 1.39(0.42), \mathrm{p}=0.07)$. In the 12 patients without restenosis, WMSI in the revascularised territories improved from 1.71 $(0.37)$ to $1.34(0.47)$ ( $\mathrm{p}=0.008)$. In contrast, there was no significant change in the WMSI in the non-revascularised territories (fig 3). There was an inverse correlation between baseline ejection fraction and global WMSI $(r=-0.7$; $\mathrm{p}=0.001)$ and between post-PTCA ejection fraction and global WMSI $(r=-0.69$; $\mathrm{p}=0.001)$.

\section{FDG UPTAKE AND OUTCOME}

Overall, the glucose metabolic rate in normal segments was significantly higher than in dysfunctional segments. There was a stepwise decrease in the mean MRG with worsening of segmental function $(\mathrm{p}<0.05)$ (fig 4$)$. There were significant differences between the MRG in normal segments and hypokinetic/akinetic segments $(p<0.01)$ and between the MRG in hypokinetic segments and akinetic segments $(\mathrm{p}<0.05)$. There was a strong correlation between regional MRG and functional outcome $(r=0.82 ; \mathrm{p}<0.0001)$, and dysfunctional segments that improved after revascularisation had a greater MRG than segments that did not improve $(0.40(0.10) v 0.21(0.16)$ $\mu \mathrm{mol} / \mathrm{g} / \mathrm{min}, \mathrm{p}<0.0001)$.

\section{PREDICTIVE VALUE OF PET AND EFFECT OF} RESTENOSIS

The proportion of dysfunctional segments that improved after PTCA increased linearly with the MRG value $(r=0.9)$. To determine the MRG threshold value above which the best prediction of improvement in functional class of at least one grade could be obtained, a receiver-operator characteristic curve (ROC) ${ }^{28}$ was constructed (fig 5). According to this analysis the optimal operating point on the curve (point of best compromise between sensitivity and specificity) was at the MRG threshold value of $0.25 \mu \mathrm{mol} / \mathrm{g} / \mathrm{min}$. In the 15 patients with angiographic follow up, when an MRG value of equal or greater than $0.25 \mu \mathrm{mol} / \mathrm{min} / \mathrm{g}$ was selected to identify viability, 32 of 33 segments that improved after PTCA were PET viable (sensitivity $97 \%$ ) and 23 of 30 segments that remained unchanged after PTCA were PET non-viable (specificity $77 \%$ ). Thirty two of 39 PET viable segments improved after PTCA (positive predictive accuracy $82 \%$ ) and 23 of 24 PET non-viable segments remained unchanged after PTCA (negative predictive accuracy 96\%). However, when patients with restenosis were excluded, specificity improved to $90 \%$ and positive predictive accuracy to $93 \%$ whereas sensitivity (97\%) and negative predictive accuracy (95\%) remained unchanged.

MYOCARDIAL BLOOD FLOW AND CORONARY FLOW RESERVE

Before PTCA resting myocardial blood flow in dysfunctional but PET viable regions was comparable with that in regions with normal function $(0.82(0.26) v 0.89(0.24) \mathrm{ml} / \mathrm{min} / \mathrm{g}$, NS) while coronary flow reserve was lower in the dysfunctional segments (1.55 (0.68) v 2.07 
(1.08), $p=0.03)$. In the nine patients who had post-PTCA measurement of myocardial blood flow and coronary flow reserve there was no change in resting myocardial blood flow after PTCA (0.81 (0.25) v $0.82(0.26) \mathrm{ml} / \mathrm{min} / \mathrm{g}$, NS), whereas coronary flow reserve improved significantly (2.03 (1.25) $v 2.33$ (1.4), $\mathrm{p}=0.03)$ in segments supplied by arteries without restenosis. Similarly, improvement in wall motion score of dysfunctional segments after PTCA was associated with a change in coronary flow reserve (from $1.68(0.77)$ to 2.25 (1.35); $\mathrm{p}=0.06)$ but not in resting myocardial blood flow $(0.89(0.3) v 0.76(0.19) \mathrm{ml} / \mathrm{min} / \mathrm{g}$, NS).

\section{Discussion}

In this paper we address three main issues in patients with hibernating myocardium and coronary artery disease: the value of PTCA and the effect of restenosis on the functional outcome; the predictive value of quantitative FDG PET; and the pathophysiological role of coronary flow reserve in this group of patients.

\section{PTCA AND MYOCARDIAL HIBERNATION}

Although the number of patients with coronary artery disease and left ventricular dysfunction undergoing PTCA is constantly increasing, ${ }^{29}$ the efficacy of this procedure for the treatment of myocardial hibernation has not been adequately tested. In particular, it is important to assess the value of PTCA in those patients with only one or two vessel disease and localised regional myocardial dysfunction, as CABG may not be indicated in many of these patients. Previous studies have generally included a mixture of patients treated with PTCA or CABG as the method of revascularisation. In addition, in most cases the chronicity of left ventricular dysfunction was assumed rather than proven by repeated measurement of left ventricular function before revascularisation. Finally, in most cases the short and long term success of revascularisation was not systematically assessed. Our present study included only patients with stable coronary artery disease and persistent left ventricular dysfunction-proven by repeated evaluation of regional left ventricular function-who underwent successful PTCA. In addition, follow up angiography was carried out to assess the long term success of revascularisation. The results of our study confirm that PTCA can improve ventricular function in patients with chronically dysfunctional but viable myocardium, and that the improvement in global function is attributable only to functional improvement in the revascularised territories. Although there are some studies ${ }^{30-32}$ that have tested the effect of restenosis on functional outcome after PTCA, to our knowledge there is only one in which myocardial viability was assessed. ${ }^{33}$ That study, however, also included patients who had undergone surgical revascularisation. Our results are in agreement with the above studies in showing that restenosis may prevent functional improvement of viable tissue following an initially successful revascularisation. This indicates that restenosis should be suspected after PTCA if dysfunctional segments, identified to be viable before revascularisation, fail to improve. The demonstration that functional improvement occurs only in revascularised regions and the failure of recovery after restenosis confirm that successful revascularisation is the reason for recovery of hibernating myocardium.

DIAGNOSTIC ACCURACY OF QUANTITATIVE PET The diagnostic accuracy of PET in detecting myocardial viability prior to coronary revascularisation has been examined in several studies. ${ }^{5-12}{ }^{13-17}$ In most of these, the PET methodology used was qualitative or semiquantitative and depended on the simultaneous assessment of myocardial perfusion and metabolism. FDG PET during euglycaemic hyperinsulinaemic clamp provides excellent image quality and enables PET studies to be performed under standardised metabolic conditions. ${ }^{34} 35$ This allows comparison of the absolute values of the metabolic rate of glucose among different subjects. In addition, this approach circumvents the problems of poor image quality in patients with insulin resistance, a condition commonly found in many patients with coronary artery disease even in the absence of diabetes and hypertension. ${ }^{25}$ Despite these advantages, only limited data are available on the diagnostic accuracy of this quantitative approach in identifying hibernating myocardium. ${ }^{25}$ Our present study shows that quantitative PET has a very high diagnostic accuracy. Previous studies have shown variable predictive accuracy for this technique. ${ }^{37}$ There may be several reasons for this:

- A different dietary protocol during FDG acquisition (fasting or glucose load).

- A heterogeneous study population consisting of patients with true hibernation and stunned myocardium, as discussed above.

- A lack of follow up angiographic data to assess the adequacy of perfusion and vessel patency: failure of functional recovery of viable tissues owing to inadequate reperfusion, restenosis, or graft failure may lead to an apparently higher false positive rates affecting the specificity and positive predictive value of the viability test.

- Variation in the duration of the follow up period: the time course of functional recovery after revascularisation may differ according to the severity of histological changes, the degree of cellular dedifferentiation, and fibrosis within hibernating tissues; more dysfunctional segments may have more extensive cellular changes ${ }^{38}$ and may require a longer time ${ }^{40}$ to recover. Specificity and positive predictive accuracy of viability studies may therefore be influenced by timing of follow up study after revascularisation. In studies that include patients with more severe left ventricular dysfunction, with a relatively high proportion of akinetic or dyskinetic segments, a single follow up study three to six months after revascularisation may lead to an underestimation of the amount of recoverable tissue. In the present study, although there was only a single follow up study after PTCA, the majority 
of dysfunctional segments (76\%) were hypokinetic and therefore the timing of the follow up study (at a mean of four months after PTCA) was probably adequate to allow for the recovery of function in the viable regions.

- Effects of different revascularisation techniques: assessment of left ventricular function after surgical revascularisation is confounded by several factors: myocardial injury or infarction may be difficult to diagnose during or soon after surgery, which may affect the chances of recovery of viable segments; open heart surgery is known to result in paradoxical or abnormal septal wall motion without evidence of any perfusion abnormality ${ }^{41}{ }^{42}$; and following CABG there may be a prolonged period of myocardial stunning. These limitations do not apply to revascularisation by PTCA. Using PTCA as the sole method of revascularisation, as in the present study, may therefore be more appropriate for defining the diagnostic accuracy of viability tests.

In order to obtain the true diagnostic value of any viability testing the confounding factors mentioned above all need to be addressed.

MYOCARDIAL BLOOD FLOW, CORONARY FLOW RESERVE, AND MYOCARDIAL VIABILITY

When hibernation was originally described it was thought to be the result of a gradual downregulation of myocardial metabolism, and hence contractile ability, in response to the reduction in resting blood flow caused by coronary artery stenosis. ${ }^{4}$ However, this idea has recently been challenged by the demonstration that myocardial blood flow in most hibernating myocardial segments may not be different from that in remote normally contracting myocardium, ${ }^{25}{ }^{43-45}$ and that resting myocardial blood flow in humans is not affected by stenosis severity. ${ }^{46}$ Our data are in agreement with these findings ${ }^{25} 4344$ and indicate that when myocardial blood flow is measured in water perfusible tissue, excluding scar tissue, the mean value obtained in hibernating segments $(0.82(26) \mathrm{ml} / \mathrm{min} / \mathrm{g})$ is within what is regarded to be the normal range. ${ }^{47}$ Furthermore, there was no significant change in resting myocardial blood flow in dysfunctional segments after PTCA, although many of these segments recovered after the procedure. Animal studies have shown that repeated episodes of ischaemia may lead to persistent wall motion abnormalities. ${ }^{48}$ It has been hypothesised ${ }^{25} 44$ that this could be the mechanism of hibernation in patients with coronary artery disease, in whom resting myocardial blood flow is within normal limits.

In our present study coronary flow reserve was significantly impaired in hibernating segments compared with normal segments, and improvement in wall motion score after PTCA was associated with an improvement in coronary flow reserve and not in resting myocardial blood flow. This supports the hypothesis that repeated episodes of ischaemia-probably caused by the severely limited coronary flow reserve-followed by prolonged postischaemic dysfunction may be the cause of hibernation. A more detailed description of the potential mechanisms of hibernation and the techniques used for its detection has been recently reported elsewhere. ${ }^{450}$

\section{LIMITATIONS}

The number of patients in the study was small. This disadvantage, however, was compensated for in some degree by the highly selective patient recruitment and follow up. Only one assessment of left ventricular function was carried out after PTCA and the period of follow up may not have been long enough, as discussed above. Although there was a good correlation between wall motion score and ejection fraction both before and after PTCA, echocardiography may not be an ideal method of assessing ejection fraction. While improvement in left ventricular function after PTCA is an important clinical finding, our study lacks data on other important clinical factors such as symptom relief, exercise capacity, quality of life, and prognosis. This is particularly important if PTCA is going to be recommended for patients with left ventricular dysfunction and hibernating myocardium.

\section{CONCLUSIONS}

Our study shows that PTCA can improve regional and global myocardial function in patients with hibernating myocardium and that restenosis may prevent this recovery. After PTCA, restenosis should be considered if there is failure of recovery of dysfunctional regions that were considered viable on cardiac imaging before the procedure. Further studies are required to identify the prognostic value of this improvement. We have also shown that quantitative FDG PET during insulin clamp has a very high diagnostic accuracy. Studies aimed to test the accuracy of the techniques used to predict hibernation need to determine the adequacy of reperfusion and vessel patency at follow up. Finally, this study concurs with several recent ones in showing that myocardial hibernation seems to be characterised by an impairment of coronary flow reserve rather than a reduction in resting myocardial blood flow.

This paper was presented in part at the meeting of the European Society of Cardiology in Birmingham, August 1996, and at the American Heart Association meeting in Anaheim, November 1996. We would like to express our gratitude to the radiochemists of the MRC Cyclotron Unit for the preparation of radiotracers, and to $\mathrm{Mr}$ Andrew Blythe, Ms Andreann Williams, and Mrs tope McDevit for their hs Andreanna Williams, and Mrs Hope McDevitt for their help in the acquisiMs Heather Boyd for her help and expertise in the data analyMs
sis.

1 Gruentzig AR, Senning A, Siegenthaler WE. Non-operative dilatation of coronary artery stenosis. $N$ Engl $\mathcal{f}$ Med 1979;301:1-8

2 Pocock SJ, Henderson RA, Rickards AF, et al. Meta-analysis of randomised trials comparing coronary angioplasty with bypass surgery. Lancet 1995;346:1184-9.

3 DiSciascio G, Cowley MJ, Vetrovec GW, et al. Triple vessel coronary angioplasty: acute outcome and long term results. 7 Am Coll Cardiol 1988;12:42-8.

4 Rahimtoola SH. A prospective on three large multicenter randomised clinical trials of coronary bypass surgery for randomised clinical trials of coronary bypass surgery for
chronic stable angina. Circulation 1985;72(suppl V): V1230-5.

5 Tillisch J, Brunken R, Marshall R, et al. Reversibility of cardiac wall-motion abnormalities predicted by positron tomography. N Engl f Med 1986;314:884-8. 
6 Tamaki N, Yonekura Y, Yamashita K, et al. Positron emission tomography using fluorine-18 deoxyglucose in evaluation of coronary artery bypass grafting. Am 7 Cardio 1989;64:860-5.

7 Lucignani G, Paolini G, Landoni C, et al. Presurgical identification of hibernating myocardium by combined use of technetium-99m hexakis 2-methoxyisobutylisonitrile single photon emission tomography and fluorine-18 fluoro-2deoxy-D-glucose positron emission tomography in patients with coronary artery disease. Eur f Nucl Med 1992;19:87481 .

8 Shivalkar B, Maes A, Borgers M, et al. Only hibernating myocardium invariably shows early recovery after coronary revascularization. Circulation 1996;94:308-15.

9 Di Carli M, Asgarzadie F, Schelbert H, et al. Quantitative relation between myocardial viability and improvement in heart failure symptoms after revascularization in patients with ischemic cardiomyopathy. Circulation 1995;92:3436644.

10 vom Dahl J, Eitzman DT, al Aouar ZR, et al. Relation of regional function, perfusion, and metabolism in patients with advanced coronary artery disease undergoing surgical revascularization. Circulation 1994;90:2356-66.

11 Tamaki N, Kawamoto $M$, Takahashi N, et al. Prognostic value of an increase in fluorine-18 deoxyglucose uptake in patients with myocardial infarction: comparison with stress thallium imaging. $7 \mathrm{Am}$ Coll Cardiol 1993;22:1621-7.

12 Tamaki N, Kawamoto M, Tadamura E, et al. Prediction of reversible ischemia after revascularization. Perfusion and metabolic studies with positron emission tomography. Circulation 1995;91:1697-705.

13 Lee KS, Marwick TH, Cook SA, et al. Prognosis of patients with left ventricular dysfunction, with and without viable myocardium after myocardial infarction. Relative efficacy of medical therapy and revascularization. Circulation 1994 90:2687-94.

14 Marwick TH, MacIntyre WJ, Lafont A, et al. Metabolic responses of hibernating and infarcted myocardium to revascularization. A follow-up study of regional perfusion, revascularization. A follow-up study of regional perfusion,

15 Gropler RJ, Geltman EM, Sampathkumaran K, et al. Comparison of carbon-11-acetate with fluorine-18fluorodeoxyglucose for delineating viable myocardium by positron emission tomography. $\mathcal{F}$ Am Coll Cardiol 1993;22 1587-97.

16 Knuuti MJ, Saraste M, Nuutila P, et al. Myocardial viability: fluorine-18-deoxyglucose positron emission tomography in prediction of wall motion recovery after revascularization. Am Heart f 1994;127:785-96.

17 Eitzman D, al Aouar Z, Kanter HL, et al. Clinical outcome of patients with advanced coronary artery disease after viability studies with positron emission tomography. $\mathcal{f} \mathrm{Am}$ Coll Cardiol 1992;20:559-65.

18 Nienaber CA, Brunken RC, Sherman CT, et al. Metabolic and functional recovery of ischemic human myocardium after coronary angioplasty. F Am Coll Cardiol 1991;18:96678 .

19 Afridi I, Kleiman NS, Raizner AE, et al. Dobutamine echocardiography in myocardial hibernation. Optimal dose and accuracy in predicting recovery of ventricular function after coronary angioplasty. Circulation 1995;91:663-70.

20 Berger PB, Holmes DR, Ohman EM, et al. Restenosis, reocclusion and adverse cardiovascular events after successfu balloon angioplasty of occluded versus nonoccluded coronary arteries. Results from the multicenter American research trial with cilazapril after angioplasty to prevent transluminal coronary obstruction and restenosis (MARCATOR). F Am Coll Cardiol 1996;27:1-7.

21 Holmes DR, Vallbracht C, Kadel C. Restenosis after percutaneous transluminal coronary angioplasty (PTCA): a report from the PTCA registry of the National Heart, Lung and Blood Institute. Am F Cardiol 1984;53:77-81c.

22 Popma JJ, Topol EJ. Factors influencing restenosis after coronary angioplasty. Am f Med 1990;88:16-24N.

23 Schiller NB. Committee of standards, subcommittee on quantification of two-dimensional echocardiograms. Recommendation for quantification of the left ventricle two-dimensional echocardiography. $\mathcal{F} \mathrm{Am}$ Soc Echocardiogr 1989;5:358-67.

24 De Fronzo RA, Jordan DT, Reubin A. Glucose clamp technique: a method for quantifying insulin secretion and
resistance. Am $\mathcal{F}$ Physiol 1979; 237:E214-23.

25 Marinho NVS, Keogh BE, Costa DC, et al. Pathophysiology of chronic left ventricular dysfunction: New insights from the measurement of absolute myocardial blood flow and glucose utilization. Circulation 1996;93:737-44.

26 Spinks TJ, Jones T, Gilardi MC, et al. Physical performance of the latest generation of commercial positron scanner. IEEE Trans Nucl Sci 1988;35:721-5.
27 Araujo LI, Lammerstma AA, Rhodes CG, et al. Noninvasive quantification of regional myocardial blood flow in
normal volunteers and patients with coronary artery normal volunteers and patients with coronary artery disease using oxygen-15 labelled carbon dioxide and posi-

28 Armitage P, Berry G. Statistical methods in medical research. Oxford: Blackwell Science, 1994.

29 Detre K, Holubkov R, Kelsey S, et al. Percutaneous transluminal coronary angioplasty in 1985-1986 and 1977-1981. Engl F Med 1988;318:265-70.

30 vom Dahl J, Uebis R, Sheehan FH, et al. Factors influencing outcome of regional wall motion following percutaneous transluminal angioplasty. Coronary Artery Dis 1992;3:48998.

31 Melgares R, Prieto JA, Azpitarte J. Significant coronary restenosis limits the recovery of regional left ventricular myocardial dysfunction achieved after successful coronary cardial dysfunction achieved after success

32 Miketic S, Carlsson J, Tebbe U. Improvement of global and regional left ventricular function by percutaneous transluminal coronary angioplasty after myocardial infarction. $\mathcal{F}$ Am Coll Cardiol 1995; 25:843-7.

33 vom Dahl J, Altehoefer C, Sheehan FH, et al. Recovery of regional left ventricular dysfunction after coronary revascularization. Impact of myocardial viability assessed by nuclear imaging and vessel patency at follow-up angiography. F Am Coll Cardiol 1996;28:948-58.

34 Tamaki N, Yonekura Y, Konishi J. Myocardial FDG PET studies with the fasting, oral glucose-loading or insulin clamp methods. F Nucl Med 1992;33:1263-8.

35 Schelbert HR. Euglycemic hyperinsulinemic clamp and oral glucose load in stimulating myocardial glucose utilisation during positron emission tomography. 7 Nucl Med 1992;33. 1263-6.

36 Paternostro G, Camici PG, Lammerstma AA, et al. Cardiac and skeletal muscle insulin resistance in patients with coronary heart disease. A study with positron emission tomography. F Clin Invest 1996;98:2094-9.

37 Maddahi J, Schelbert H, Brunken R, et al. Role of thallium201 and PET imaging in evaluation of myocardial viability and management of patients with coronary artery disease and left ventricular dysfunction. F Nucl Med 1994;35:70715

38 Ausma J, Furst D, Thone F, et al. Molecular changes of titin in left ventricular dysfunction as a result of chronic hibernation. F Mol Cell Cardiol 1995;27:1203-12.

39 Ausma J, Cleutjens J, Thone F, et al. Chronic hibernating myocardium: interstitial changes. Mol Cell Biochem 1995; 147:35-42.

40 Vanoverschelde JL, Janier MF, Bakke JE, et al. Rate of glycolysis during ischemia determines extent of ischemic injury and functional recover

41 Vignola P, Boucher C, Curfman G. Abnormal interventricular septal motion following cardiac surgery: clinical, surgical, echocardiographic and radionuclide correlates. Am Heart 7 1979;97:27-34.

42 Okada RD, Murphy JH, Boucher CA, et al. Relationship between septal perfusion, viability, and motion before and after coronary artery bypass surgery. Am Heart $\mathcal{F}$ 1992;124: $1190-5$.

43 Gerber BL, Vanoverschelde JL, Bol A, et al. Myocardial blood flow, glucose uptake, and recruitment of inotropic reserve in chronic left ventricular ischemic dysfunction: implications for the pathophysiology of chronic myocardial hibernation. Circulation 1996;94:651-9.

44 Vanoverschelde JL, Wijns W, Depre C, et al. Mechanisms of chronic regional postischemic dysfunction in humans. New insights from the study of noninfarcted collateraldependent myocardium. Circulation 1993;87:1513-23.

45 Maki $M$, Luotolahti $M$, Nuutila P. Glucose uptake in the chronically dysfunctional but viable myocardium. Circulation 1996;93:1658-6.

46 Uren NG, Melin JA, De Bruyne B, et al. Relation between myocardial blood flow and the severity of coronary artery myocardial blood flow and the severity of
stenosis. N Engl f Med 1994;330:1782-8.

47 Bergmann SR, Herrero P, Markham J, et al. Noninvasive quantitation of myocardial blood flow in human subjects quantitation of myocardial blood flow in human subjects with oxygen-15-labeled water and positron

48 Shen YT, Vatner SF. Mechanism of impaired myocardial function during progressive coronary stenosis in conscious pigs. Hibernation versus stunning? Circ Res 1995;76:47988

49 Camici PG, Wijns WC, Borgers M, et al. Pathophysiological mechanisms of chronic reversible left ventricular dysfunction due to coronary artery disease (hibernating myocardium). Circulation 1997; 96: 3205-14.

50 Wijns W, Vatner SF, Camici PG. Chronic reversible left ventricular dysfunction in patients with coronary artery disease a.k.a. hibernating myocardium. $N$ Engl f Med 1998; 339:173-81. 